\title{
Early Participation in a Prenatal Food Supplementation Program Ameliorates the Negative Association of Food Insecurity with Quality of Maternal-Infant Interaction ${ }^{1-3}$
}

\author{
Amy L. Frith, ${ }^{4,5}$ Ruchira T. Naved, ${ }^{6}$ Lars Ake Persson, ${ }^{7}$ Kathleen M. Rasmussen, ${ }^{5}$ \\ and Edward A. Frongillo ${ }^{8}$ \\ ${ }^{4}$ School of Health Sciences and Human Performance, Ithaca College, Ithaca, NY; ${ }^{5}$ Division of Nutritional Sciences, Cornell University, \\ Ithaca, NY; ${ }^{6}$ International Centre for Diarrhoeal Disease Research, Bangladesh, Dhaka, Bangladesh; ${ }^{7}$ Women's and Children's Health, \\ International Maternal and Child Health, Uppsala University, Uppsala, Sweden; and ${ }^{8}$ Department of Health Promotion, Education, and \\ Behavior, University of South Carolina, Columbia, SC
}

\begin{abstract}
Food insecurity is detrimental to child development, yet little is known about the combined influence of food insecurity and nutritional interventions on child development in low-income countries. We proposed that women assigned to an early invitation time to start a prenatal food supplementation program could reduce the negative influence of food insecurity on maternal-infant interaction. A cohort of 180 mother-infant dyads were studied (born between May and October 2003) from among 3267 in the randomized controlled trial Maternal Infant Nutritional Interventions Matlab, which was conducted in Matlab, Bangladesh. At 8 wk gestation, women were randomly assigned an invitation time to start receiving food supplements (2.5 MJ/d; $6 \mathrm{~d} / \mathrm{wk}$ ) either early ( 9 wk gestation; early-invitation group) or at the usual start time ( 20 wk gestation; usualinvitation group) for the government program. Maternal-infant interaction was observed in homes with the use of the Nursing Child Assessment Satellite Training Feeding Scale, and food-insecurity status was obtained from questionnaires completed when infants were 3.4-4.0 mo old. By using a general linear model for maternal-infant interaction, we found a significant interaction ( $P=0.012$ ) between invitation time to start a prenatal food supplementation program and food insecurity. Those in the usual-invitation group with higher food insecurity scores (i.e., more food insecure) had a lower quality of maternal-infant interaction, but this relationship was ameliorated among those in the early-invitation group. Food insecurity limits the ability of mothers and infants to interact well, but an early invitation time to start a prenatal food supplementation program can support mother-infant interaction among those who are food insecure. J. Nutr. 142: 1095-1101, 2012.
\end{abstract}

\section{Introduction}

Approximately 200 million children do not reach their potential cognitive development, which leads to poor future school and economic performance (1). A child's cognitive, social, and

\footnotetext{
${ }^{1}$ Supported by the American Institute of Bangladesh Studies, the Cornell Einaudi Center for International Studies, and the NIH (training grant 5T32DK07158). The Maternal Infant Nutritional Interventions Matlab (MINIMat) research study was funded by UNICEF; the Swedish International Development Cooperation Agency; the U.K. Medical Research Council; the Swedish Research Council; the Department of International Development; International Centre for Diarrhoeal Disease Research, Bangladesh; Global Health Research Fund-Japan; Child Health and Nutrition Research Initiative, Uppsala University; and the U.S. Agency for International Development. In addition, the ICDDR, B acknowledges with gratitude the commitment of these donors to the Centre's research efforts and gratefully acknowledges the following donors that provided unrestricted support to the Centre's research efforts: the Australian International Development Agency, the Government of Bangladesh, the Canadian International Development Agency, the government of Japan, the government of the Netherlands, the Swedish International Development Cooperation Agency, the Swiss Development Cooperation, and the Department of International Development.
}

behavioral development is built on high-quality maternal-infant interaction (2) during early infancy (3,4). Maternal-infant interaction is a combination of maternal caring behaviors and infant behavior to elicit and respond to maternal care (5) and requires that both mother and infant have the physical and mental resources to be proactive and responsive. In highincome countries, pre- and postnatal maternal stress and malnutrition impinge on the necessary conditions for mothers to provide high-quality care $(6,7)$, for infants to elicit care $(8)$, or both $(7,9)$. Little is known about these relationships in lowincome countries (10-12), such as in Bangladesh, where many infants suffer from compromised development $(13,14)$.

Food insecurity is a stressor (15-17) that has been linked to poor parenting, quality of parent-child relationships $(3,17-19)$,

\footnotetext{
${ }^{2}$ Author disclosures: A. L. Frith, R. T. Naved, L. A. Persson, K. M. Rasmussen, and E. A. Frongillo, no conflicts of interest.

${ }^{3}$ The MINIMat study was registered at controlled-trials.com as ISRCTN16581394.

* To whom correspondence should be addressed. E-mail: afrith@ithaca.edu.
} 
child developmental outcomes (3,14,20-22), and to depression and distress in mothers $(3,15,17)$. Stressors are events or situations that produce a stress response, such as depression and distress (23). The presence or absence of external resources determines in part whether stressors influence developmental outcomes. Food insecurity potentially increases stress responses through psychological mechanisms associated with uncertainty, deprivation, and alienation $(15,22)$ or through physiologic mechanisms via lack of nutrients $(24)$ or both $(9,15,22)$. Food insecurity, depression, and distress increase fatigue, illness, sadness, loss of interest, and intrusiveness $(4,17,25-28)$, which can reduce the mother's ability to provide sensitive and responsive parenting $(17,29,30)$. This may lead to poor maternal-child interaction (3), less secure attachments $(4,17,27)$, and poor child development $(13,14,29,30)$. Whether a nutritional intervention as an external resource (31) can attenuate the consequences of food insecurity on quality of maternal-infant interaction is unclear.

Prenatal food programs provide food and social contact that could influence maternal-infant interaction by improving the nutrient intake and mental health of mothers, the growth and development of the fetus (32), or a combination of these (33). Poor maternal dietary intake reduces quality of caregiving $(12,34)$ and increases maternal depression (35). Poor maternal nutrition may impair maternal-child interactions in part through increased maternal depression (9). Poor maternal nutrition also limits fetal growth and development, thereby increasing negative infant behaviors and reducing the quality of maternal-infant interaction (36). The influence of food programs may depend on timing and amount of supplement provided and on conditions under which mothers live $(9,33)$. The timing of food supplementation may influence fetal growth and development by preventing early deficits (37) and by increasing the overall amount of food a woman consumes. The amount of food may be important because pregnant women in low-income countries who consumed more food supplement (>83.8 MJ) had heavier infants than did those who consumed less food supplement $(<83.3 \mathrm{MJ})$ (38) and increased birth weight is associated with better quality of maternal-infant interaction $(39,40)$.

Food insecurity can be detrimental to prenatal nutrition, maternal mental health, and maternal-infant interaction. Thus, a food program that begins earlier in pregnancy can offer women earlier access to adequate intake as well as a higher total nutrient intake, which may support better quality of maternal-infant interaction than does a food program that begins later, particularly among women who are more food insecure. In a cohort of mother-infant dyads in rural Bangladesh, we proposed that food insecurity would be detrimental to maternal-infant interaction in the usual-invitation group (i.e., later invitation) but not in the early-invitation group.

\section{Participants and Methods}

Study design and sample. This investigation was part of a larger study, the Maternal Infant Nutritional Interventions Matlab (MINIMat). The selection and recruitment of the participants were described elsewhere (34). In brief, this research was conducted between June 2003 and January 2004 in Matlab, which is a subdistrict of the Chandpur district that is typical of the rural and riverine delta of Bangladesh (41). Written, informed consent was obtained from each woman before enrollment. The institutional review boards of the International Centre for Diarrheal Research, Bangladesh, and Cornell University approved the study protocol. The participants for this investigation were recruited from all eligible MINIMat participants $(n=3267)$ who had the following characteristics: 1) they had given birth between May and October 2003 in 2 of 4 health centers and 2) their infants were 3.4-4.0 mo of age, singleton, and free of obvious congenital anomalies. We recruited chronologically until we reached a total of 202 mother-infant dyads. Community health workers first visited eligible MINIMat participants to explain the study and to gain permission for researchers to visit their home and obtain informed consent. Of the 202 mother-infant dyads who were recruited, 180 were observed for maternal-infant interaction. Twenty-two did not participate because 2 infants were ill, 2 mothers refused to participate, and 18 mothers were not at home when the infant was the correct age. In this population, at $\sim 9 \mathrm{wk}$ of gestation, $40.7 \%$ of participants were chronically malnourished, characterized by a low BMI $\left(<18.5 \mathrm{~kg} / \mathrm{m}^{2}\right)$. In an earlier study in this population, pregnant women from 5 to $6 \mathrm{mo}$ of gestation consumed $6.13 \mathrm{MJ} / \mathrm{d}$, which is below recommendations (42).

MINIMat was a randomized, double-blind, controlled field trial with a $3 \times 2 \times 2$ factorial design. Pregnant women at 8 wk of gestation were randomly and independently assigned to receive 1 of each of the 3 nutritional interventions. Each participant was assigned to a food supplementation group, either at an early invitation time to start daily food supplementation ( $2.5 \mathrm{MJ} / \mathrm{d} ; 6 \mathrm{~d} / \mathrm{wk}$ ) ( $\sim 9 \mathrm{wk}$ of gestation; earlyinvitation group) or at the usual invitation time to start participation ( $\sim 20$ wk of gestation; usual-invitation group) in the governmental program, until she gave birth. Each participant was also assigned to receive 1 of 2 counseling protocols from $30 \mathrm{wk}$ of gestation until 6 mo after giving birth, either health counseling alone or health with exclusive breastfeeding counseling. Beginning at 14 wk of gestation until 3 mo postpartum, each participant received daily micronutrient supplementation of either 60 or $30 \mathrm{mg}$ of iron with $400 \mu \mathrm{g}$ folic acid or multiple micronutrients (30 mg iron with the UNICEF formulation) (34). For this investigation, the types of counseling and micronutrient supplementation were ignored after we established that these interventions did not modify the relationship of food insecurity on maternal-infant interaction; using ANOVA, we found that interaction terms were not significant for food insecurity and types of counseling $(P$-interaction $=0.53)$ or food insecurity and types of micronutrient supplement $(P$-interaction $=0.57)$.

Pregnant women received and consumed the food supplements, which were supplied as individual packets daily for $6 \mathrm{~d} / \mathrm{wk}$ by a community nutrition educator at a community nutrition center from the assigned invitation time to start (i.e., early or usual) until $8 \mathrm{mo}$ of gestation. The community nutrition educators were local women who were trained by the implementing organization, BRAC, to deliver nutrition education messages and to encourage women to consume food packets completely on site. From 8 mo of gestation until birth, food supplements were delivered to participants' homes. Supplement consumption was monitored by monthly questionnaires. The composition of the food supplement was in accordance with the U.S.-recommended daily allowance $(43,44)$, and the supplement was intended as a snack to supplement, not replace, home food consumption. The supplement contained rice, lentils, molasses, and oil and contained $608 \mathrm{kcal}$ (2.5 MJ; $29 \%$ of the recommended energy intake) and $18 \mathrm{~g}$ of vegetable protein. The consistency was culturally acceptable because it was based on a common type of food. In the main MINIMat study, the early-invitation group began consumption $\sim 2.5$ mo earlier and, on average, consumed more supplement packets over the course of the pregnancy (105 packets) than did the usual-invitation group (66 packets). In this substudy, the early-invitation group consumed more packets than did the usual-invitation group $(92 \pm 41$ and $75 \pm 39$, respectively; $P<0.05)$.

Measures. Maternal characteristics, including parity, age, education, socioeconomic status, and food insecurity during early pregnancy, were assessed by questionnaire at 8 to $9 \mathrm{wk}$ of gestation. A wealth index was used to assess socioeconomic status on the basis of a composite of information about land ownership, characteristics of the household dwelling, and household ownership of durables (i.e., bed, quilt, mattress, watch/clock, chair/table, cabinet, bicycle, radio, television, electric fan, cows, goats, chicken/ducks) (45). Maternal height and weight were also measured at 8 to $9 \mathrm{wk}$ of gestation. Trained health workers measured and collected information on infant characteristics, including gender and birth weight $(\mathrm{g})$, within the first $4 \mathrm{~d}$ of birth for $90 \%$ of the sample, and within $30 \mathrm{~d}$ of birth for the remaining infants.

Postpartum food insecurity was measured by using a questionnaire administered to mothers $1 \mathrm{~d}$ after the maternal-infant interaction 
observation, when infants were $3.4-4.0$ mo of age, by researchers who were different from those who observed the interaction. The food insecurity questionnaire was an 11-item, experienced-based measure developed to assess food insecurity by asking mothers about food availability, food access, and perceptions of food insecurity, which included whether the mother worries or is anxious about obtaining food (46), and has been used previously in this population $(13,14)$. The items were scored and summed to create a continuous variable, with higher scores corresponding to more severe food insecurity; the possible range was 9 to 42 . We also categorized the sample into 2 groups, severely food insecure and occasionally to moderately food insecure or food secure, by choosing the cutoff (i.e., score of 17) that represented the highest score possible that corresponded to no indications of severe food insecurity. Indications of severe food insecurity (in the past $30 \mathrm{~d}$ ) were as follows: purchasing rice more than twice a week, buying perishable food items $<4$ times a week, cooking less than twice a day, not helping others to make a meal, borrowing from others to make a meal, having fewer than 3 fulfilling meals per day, not having fulfilling meals, not having snacks between meals, having fish less than twice a week, or having to eat rice with only salt and chili (46). This cutoff resulted in $34 \%$ of dyads falling within the category of severe food insecurity.

Food insecurity was measured by using the same questionnaire (46) at $\sim 9 \mathrm{wk}$ and $30 \mathrm{wk}$ of gestation as well as postpartum (i.e., when infants were 3.4-4 mo of age). We focused on the postpartum food insecurity scores because we were most interested in determining how a prenatal nutrition intervention influenced a postpartum outcome, and the postpartum food insecurity scores corresponded with the time that the outcome behaviors were measured. For $86 \%$ of the participants, their pre- ( $9 \mathrm{wk}$ of gestation) and postpartum food insecurity status remained the same. Furthermore, when food insecurity scores at 9 wk of gestation were used instead of postpartum food insecurity scores in the analysis, similar results were observed.

Maternal-infant interaction during feeding was measured because it reflects the overall quality of interaction between a mother and her infant (5), and it is an integral part of care (47). The first author (A.L.F.) was trained and certified using standard procedures (reliability $>90 \%$ compared with standard scoring with video-taped scenarios) to use the Nursing Child Assessment Satellite Training Feeding Scale (NCAST) by a certified NCAST trainer (Dr. Mary Byrne, Columbia University School of Nursing, New York, NY) (5) and measured maternal-infant interaction on a single day in the participant's home. A Bengali researcher assisted in recording maternal verbalizations. All maternal-infant interactions were observed before the food insecurity questionnaire was administered to avoid influencing the interactions. The researchers minimized the impact of the observation on feeding behavior by living in the study community, having familiar local health community workers introduce them, and building rapport with the mother and family through visiting homes before they observed maternal-infant interactions.

The underlying concepts used in the NCAST are based on the attachment, developmental psychology, and psychobiology literature. The NCAST is a well-known observation tool that assesses the quality of maternal-infant interaction in both clinical and research settings to identify infants at risk for developmental delays and to measure the effects of interventions on quality of maternal-infant interaction. The behaviors of a mother and infant dyad are observed during feeding, and observations are recorded on a scale. This scale is composed of 76 behavioral descriptions of the mother, infant, or both. Behaviors are scored " 1 " if they occur and " 0 " if they do not occur. The number of scored behaviors observed is summed. Higher scores indicate a better quality of interaction. Total score, mother and infant total scores, and 7 subscale behavioral scores represent the quality of the maternal-infant interaction. The overall total score is a composite of maternal and infant scores. The maternal score comprises 4 subscales: sensitivity, response to infant distress, social emotional growth fostering, and cognitive fostering. The infant score comprises 2 subscales: clarity of cues and responsiveness to caregiver. The contingency subscale can be calculated from a combination of 15 items from the mother's scale and 3 items from the infant's scale that measure if an individual behavior (e.g., smiling, verbalization, touching) is followed by a responding behavior of the mother or infant.

The major concepts imbedded in the NCAST feeding scale are sensitivity, contingency, positioning, verbalness, affect, and engagement/ disengagement. Sensitivity measures whether the mother responds appropriately to the infant's engagement or disengagement cues. The other concepts have been described elsewhere $(5,34)$. The NCAST manual includes a detailed summary of reliability and validity information (5). In Bangladesh, we found that the internal consistencies of the total, maternal, and infant NCAST scales were $0.84,0.86$, and 0.68 , respectively, by using the Kudar-Richardson formula as described previously (28). The test-retest reliability was 0.61 for home observations (28), and NCAST scores from Bangladesh were similar to U.S. norms for other ethnic groups with a low education $(5,28)$.

Statistical analysis. The total NCAST score was used to measure the overall quality of maternal-infant interaction. We used $t$ tests to compare baseline characteristics of women in this study with those within the larger MINIMat trial. Baseline comparability of food supplementation groups was assessed by using a $t$ test for continuous variables and a chisquare test for categorical variables. We used the same approach to assess the baseline comparability of the 2 food insecurity groups. NCAST scores were normally distributed and are reported as means \pm SD.

To test our hypothesis that the invitation time to start the prenatal food supplementation modifies the relationship of food insecurity and maternal-infant interaction, we used a general linear model that included an interaction term between food-insecurity score and invitation time to start the prenatal food supplementation groups and reported 2-sided $P$ values. Food insecurity was a continuous variable in the general linear model for total NCAST score and the maternal and infant NCAST subscales. Although we previously reported that type of micronutrient group influenced maternal-infant interaction (34), neither micronutrient group nor type of counseling were confounders because they were not related to food insecurity or food supplement groups. Wealth index and maternal BMI were examined as confounding factors in the general linear model, but their inclusion as variables did not alter regression coefficients for food insecurity, food supplement group, or their interaction. We used SPSS (version 18; SPSS, Inc.) for all analyses. The power to detect differences between food-insecurity groups was determined by assuming $\alpha=0.05$, by selecting a sample size of 90 for each group, and by using 2-tailed tests. There was a power of $\geq 0.80$ to detect a difference of 2.5 in total NCAST scores (48) between 2 groups, which is the same magnitude of difference for infants with congenital heart disease and increased insecure attachments compared with infants without the disease (49) and for dyads with lower income compared with those with higher income (5). A $P$ value $<0.05$ was considered significant.

\section{Results}

There were no differences in baseline maternal or infant characteristics between those who did or did not participate in this substudy (data not shown). Baseline characteristics of the 180 mothers and infants did not differ between food supplementation groups (Table 1). Those who were severely food insecure were less wealthy than those who were food secure or occasionally to moderately food insecure $(P<0.01)$.

The relationship of food insecurity and maternal-infant interaction was modified $(P$-interaction $=0.012)$ by invitation time to start the prenatal food supplementation program (Table 2, Fig. 1). Food insecurity was associated with reduced quality of maternal-infant interaction for those assigned to the usualinvitation group. In contrast, food insecurity was not associated with reduced quality of maternal-infant interaction for those assigned to the early-invitation group.

We also examined whether the invitation time to start prenatal food supplementation attenuated the relationship of food insecurity on the mother and infant subscales. As was the case for the total NCAST score, the lowest scores for each subscale were found in the usual-invitation group who was severely food insecure (Table 3 ). That is, although not all subscales had $P$-interaction $<0.05$ (range $P=0.06$ to $P=0.12$ ), 
TABLE 1 Baseline values of demographic and anthropometric characteristics of Bangladeshi mothers and infants (3.4-4.0 mo of age) in the MINIMat study by food insecurity and invitation time to start a prenatal food supplementation group (usual invitation: $\sim 20$ wk of gestation; early invitation: $\sim 9$ wk of gestation) ${ }^{1}$

\begin{tabular}{|c|c|c|c|c|c|}
\hline & \multicolumn{2}{|c|}{ Food-insecurity scores } & \multicolumn{2}{|c|}{ Invitation time to start food supplementation } & \multirow[b]{2}{*}{ Total $(n=180)$} \\
\hline & Lower $(n=119)$ & Higher $(n=61)$ & Usual $(n=91)$ & Early $(n=89)$ & \\
\hline \multicolumn{6}{|l|}{ Mothers } \\
\hline Education, $y$ & $6.7 \pm 3.0$ & $7.1 \pm 2.9$ & $6.7 \pm 2.8$ & $7.0 \pm 3.2$ & $6.9 \pm 3.0$ \\
\hline Age, $y$ & $26.2 \pm 6.5$ & $27.6 \pm 5.5$ & $26.5 \pm 6.0$ & $26.8 \pm 6.3$ & $27.7 \pm 6.1$ \\
\hline Wealth index ${ }^{2}$ & $3.2 \pm 1.5^{*}$ & $2.3 \pm 1.4$ & $2.9 \pm 1.5$ & $2.8 \pm 1.5$ & $2.9 \pm 1.5$ \\
\hline \multicolumn{6}{|l|}{ Infants } \\
\hline Female, \% & 52.1 & 52.2 & 55.6 & 54.4 & 55.0 \\
\hline Birth weight, $g$ & $2722 \pm 358$ & $2763 \pm 350$ & $2737 \pm 368$ & $2736 \pm 343$ & $2737 \pm 355$ \\
\hline Gestational age, $w k$ & $39.3 \pm 1.7$ & $39.4 \pm 1.3$ & $39.5 \pm 1.5$ & $39.3 \pm 1.6$ & $39.4 \pm 1.5$ \\
\hline
\end{tabular}

the pattern of means for each subscale was consistent with the hypothesis that the relationship of food insecurity and maternalinfant interaction was modified by invitation time to start a prenatal food supplementation program.

\section{Discussion}

The negative association of food insecurity with maternal-infant interaction as seen in the usual-invitation group was ameliorated by the early invitation time to start the program. That is, an early invitation time to start a prenatal food supplementation program resulted in severely food-insecure mother-infant dyads exhibiting similar quality of maternal-infant interaction as foodsecure or occasionally to moderately food-insecure motherinfant dyads.

The importance of prenatal nutrition and social conditions on child health and development has been increasingly recognized $(9,29,50-53)$. Food supplementation programs influence prenatal nutrition (38) and social conditions (54) and could thereby influence maternal-infant interaction through both biological and social pathways. A potential biological pathway exists in which mothers who consume more nutrients beginning earlier in gestation experience better health and their infants have better fetal growth and development than mothers who consume fewer nutrients or consume them later in gestation $(9,33,38,55)$. As shown in animal studies, better maternal nutrition leads to better placental function and fetal development, even if fetal growth or size is not influenced (56). These developmental improvements could promote better maternalinfant interaction, especially in those households with the greatest need of supplemental food, namely those that are severely food insecure. Given that the early-invitation group had begun receiving food at about the time when intrauterine growth retardation has been shown to occur, by $8 \mathrm{wk}$ of gestation (37), and this group consumed more food supplement throughout gestation than did the usual-invitation group, earlier supplementation may have prevented poor maternal health or poor fetal growth and development in those who were severely food insecure. Inasmuch as we measured food insecurity postpartum, this explanation would be possible only if food-insecurity status was persistent from pregnancy until after delivery, which is what we observed.

Although prenatal programs may influence maternal-infant interaction through biological pathways, they may also do so through social pathways. Prenatal food programs, such as the MINIMat program in this study or the Supplemental Nutrition Program for Women, Infants, and Children in the United States provide opportunities for social contact. For example, in this study, pregnant women in the early-invitation group would have daily social contact with community nutrition educators and other pregnant women earlier in their pregnancy, and for more days in their pregnancy than those in the usual-invitation group. The increased social contact could improve emotional wellbeing $(57,58)$, particularly in those who were more severely food insecure who may have had more insults to their emotional well-

TABLE 2 General linear model for the association of food insecurity and invitation time to start a prenatal food supplementation program (usual invitation: $\sim 20 \mathrm{wk}$ of gestation; early invitation: $\sim 9$ wk of gestation) with maternal-infant interaction scores (NCAST) among Bangladeshi mothers and infants (3.4-4.0 mo of age) in the MINIMat study ${ }^{1}$

\begin{tabular}{|c|c|c|c|}
\hline & \multicolumn{2}{|c|}{ NCAST scores at $3.8-4.0 \mathrm{mo}$} & \multirow[b]{2}{*}{$P$ value } \\
\hline & $B$ & $95 \% \mathrm{Cl}$ & \\
\hline Intercept & 66.3 & $53.9,78.7$ & 0.001 \\
\hline Food insecurity ${ }^{2}$ & -0.8 & $-1.5,-0.1$ & 0.039 \\
\hline \multicolumn{4}{|l|}{ Food supplement } \\
\hline Early invitation & -20.2 & $-36.9,-3.5$ & 0.018 \\
\hline Usual invitation & 0 & - & - \\
\hline \multicolumn{4}{|l|}{ Food insecurity $\times$ food supplement } \\
\hline Food insecurity $\times$ early invitation & 1.2 & $0.3,2.2$ & 0.012 \\
\hline Food insecurity $\times$ usual invitation & 0 & - & - \\
\hline$R^{2}$ & 0.04 & & \\
\hline
\end{tabular}

${ }^{1}$ Values are $95 \%$ Wald's $\mathrm{Cl}$. MINIMat, Maternal Infant Nutritional Interventions Matlab; NCAST, Nursing Child Assessment Satellite Training Feeding Scale.

${ }^{2}$ Food insecurity was continuous, with higher scores corresponding to more severe food insecurity. 


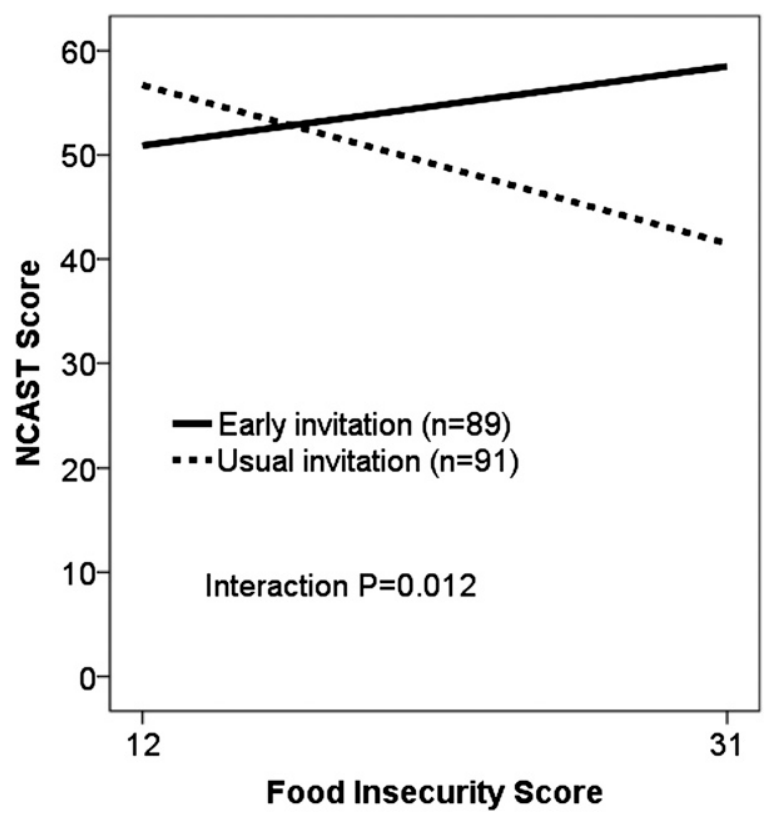

FIGURE 1 General linear model of the relationship between maternal-infant interaction scores (NCAST) and food-insecurity scores (observed range: 12-31; higher scores indicate more food insecure) by invitation time to start the prenatal food supplementation program (usual invitation at $\sim 20 \mathrm{wk}$ of gestation or early invitation at $\sim 9 \mathrm{wk}$ of gestation) among Bangladeshi mothers and infants (3.4-4.0 mo of age) in the Maternal Infant Nutritional Interventions Matlab study. NCAST, Nursing Child Assessment Satellite Training Feeding Scale.

being (59). Better maternal emotional well-being is associated with better fetal development $(60,61)$, and the effects of maternal well-being continue after delivery (61), supporting better quality of maternal-infant interaction.

That food insecurity was negatively associated with maternal-infant interaction in the usual-invitation group is consistent with results from recent studies in low- and high-income countries in which food insecurity is detrimental to child growth (13), development $(3,14,20-22)$, and the parent-child relationship $(3,17-19)$. Food insecurity may compromise the quality of maternal-infant interaction because food insecurity increases stress and depression $(17,59)$ in mothers. Food insecurity may have such effects because it is a potent stressor reflecting a lack of food, and food is a basic necessity for the survival of the mother and her family. Mothers who experience stressors (7), or responses to stress, such as depression (6), have a lower quality of maternalinfant interaction because they have difficulty in responding to their infant's needs $(6,7,30)$, show flatter affect $(50)$, and are more aggressive toward their children (49-51). Expanding on this literature, we found that in the usual-invitation group, mothers who were severely food insecure had reduced scores on response to infant distress, socioemotional growth fostering, and contingency subscales. These results indicated that the severely food-insecure mothers in the usual-invitation group had more difficulty in responding to their infants' needs, both during distress and nondistress situations, and in providing socioemotional stimulation.

Infants whose mothers experience high levels of stress or depression do not interact as well, are more irritable, and have a more difficult temperament (52) than infants whose mothers are not stressed or depressed. An infant's ability to communicate clearly and positively with a mother is important to signal when, how, and how much of a particular object or situation is needed. In this study, the lowest infant subscale NCAST scores were observed for infants of mothers who were severely food insecure and in the usual-invitation group, which shows that these infants were the least able to communicate their needs among all the groups. Given that food insecurity is a stressor, and that maternal stress is detrimental to maternal-infant interactive behaviors and child outcomes, it is possible that food insecurity sets up a negative pattern of interaction that eventually limits child growth and development $(13,14)$.

In general, the NCAST scores for this study population were similar to low-income mother-infant dyads in the United States

TABLE 3 The relationship of food insecurity and the invitation time to start a prenatal food supplementation program(usual invitation: $\sim 20$ wk of gestation; early invitation: $\sim 9$ wk of gestation) on maternal-infant interaction (NCAST) scores among Bangladeshi mothers and infants (3.4-4.0 mo of age) in the MINIMat study ${ }^{1}$

\begin{tabular}{|c|c|c|c|c|c|}
\hline \multirow[b]{3}{*}{ Feeding interaction } & \multicolumn{4}{|c|}{ Food insecurity scores } & \multirow[b]{3}{*}{$P$-interaction ${ }^{2}$} \\
\hline & \multicolumn{2}{|c|}{ Food supplement (usual time) } & \multicolumn{2}{|c|}{ Food supplement (early) } & \\
\hline & Lower $(n=66)$ & Higher $(n=25)$ & Lower $(n=53)$ & Higher $2(n=34)$ & \\
\hline \multicolumn{6}{|l|}{ Mothers } \\
\hline Total & $34.7 \pm 7.9$ & $31.8 \pm 8.0$ & $35.3 \pm 7.9$ & $35.0 \pm 8.0$ & 0.027 \\
\hline Socioemotional growth & $9.0 \pm 2.9$ & $7.6 \pm 3.0$ & $8.8 \pm 2.8$ & $8.7 \pm 3.1$ & 0.049 \\
\hline Cognitive growth fostering & $5.6 \pm 2.2$ & $4.7 \pm 2.4$ & $5.5 \pm 2.3$ & $5.4 \pm 2.4$ & $\geq 0.05$ \\
\hline \multicolumn{6}{|l|}{ Infants } \\
\hline Total & $19.2 \pm 3.4$ & $17.7 \pm 4.4$ & $18.8 \pm 3.7$ & $19.6 \pm 3.7$ & 0.019 \\
\hline Clarity of cues & $12.7 \pm 1.8$ & $12.1 \pm 2.8$ & $12.7 \pm 2.0$ & $13.0 \pm 1.8$ & $\geq 0.05$ \\
\hline Responsiveness & $6.5 \pm 1.9$ & $5.6 \pm 2.0$ & $6.1 \pm 2.0$ & $6.7 \pm 2.1$ & 0.007 \\
\hline
\end{tabular}

\footnotetext{
${ }^{1}$ Values are means \pm SD. Those with higher food insecurity scores had indications of severe food insecurity (scores above $17,34 \%$ of the dyads). Those with lower food insecurity scores had indications of food security or occasional- to- moderate food insecurity (scores below or equal to 17, $66 \%$ of the dyads). MINIMat, Maternal Infant Nutritional Interventions Matlab; NCAST, Nursing Child Assessment Satellite Training Feeding Scale.

2 -interaction of food insecurity score (continuous) and invitation time to start a prenatal food supplementation program as determined by general linear model equivalent to the model in Table 2.

${ }^{3}$ Total NCAST scores are the combination of total mother and total infant subscales.
} 
(5). The effect of invitation time to start the prenatal food supplementation program on NCAST scores was developmentally meaningful. The difference in NCAST scores between the severely food-insecure and food-secure or occasionally to moderately food-insecure mothers in the early-invitation group was $<1$ point, and in the usual-invitation group was $\sim 5$ points. This magnitude of difference in the usual-invitation group is similar to that observed between mother-infant dyads whose infants are at high versus low risk of poor developmental outcomes $(5,48)$.

Social and health conditions may affect participation and response to interventions $(33,62)$ and may limit generalizability to other contexts. This study was conducted in an area where the community has a relationship with the implementing and research institutions, and where women of childbearing age typically suffer from chronic energy deficiency. Evidence exists that the quality of early maternal-infant interaction affects later child development in the United States (5); it is unclear, however, what the benefit of early prenatal food supplementation among those who are severely food insecure may have on long-term maternal-infant interaction and how it may be linked to better child development outcomes.

Food insecurity can be detrimental to maternal-infant interaction, which could contribute to poor child development, growth, and health (2). A growing body of evidence indicates that supporting food security for families should be an ultimate goal to promote positive developmental and health outcomes for children. In a population in which food insecurity and poor nutrition are an immediate reality, however, investing in earlier prenatal food supplementation programs than is usually practiced is one strategy that can support better child outcomes.

\section{Acknowledgments}

The authors thank Shilpi Begum and Nipa Hague for their assistance in data collection and Dr. Mary Bryne of Columbia University School of Nursing (New York, NY) for the NCAST training she provided. A.L.F. led the study planning and design, collected data, wrote the manuscript, and had primary responsibility for final content; E.A.F contributed to the study design, statistical analysis of the data, and interpretation and writing of the manuscript; K.M.R. and R.T.N. contributed to the study design, interpretation of results, and critical revision of the manuscript for important intellectual content; and L.A.P. led the MINIMat study and contributed to the design and implementation of the study and revision of the manuscript. All authors read and approved the final manuscript.

\section{Literature Cited}

1. Grantham-McGregor S, Cheung YB, Cueto S, Glewwe P, Richter L; Strupp B and the International Child Development Steering Group. Developmental potential in the first 5 years for children in developing countries. Lancet. 2007;369:60-70.

2. Richter L. The importance of caregiver-child interactions for the survival and healthy development of young children. Geneva, World Health Organization; 2004.

3. Coyl DD, Roggman LA, Newland LA. Stress, maternal depression, and negative mother-infant interactions in relation to infant attachment. Infant Ment Health J. 2002;23:145-63.

4. Tomlinson M, Cooper P, Murray L. The mother-infant relationship and infant attachment in a South African peri-urban settlement. Child Dev. 2005;76:1044-54.

5. Sumner G, Spietz A. NCAST caregiver/parent-child interaction. Seattle (WA): NCAST Publications; 1994.

6. Beck CT. The effects of postpartum depression on child development: a meta analysis. Arch Psychiatr Nurs. 1998;12:12-20.
7. Belsky J. The determinants of parenting—a process model. Child Dev. 1984;55:83-96.

8. Søndergaard C, Olsen J, Friis-Hasche E, Dirdal M, Thrane N, Sorensen HT. Psychosocial distress during pregnancy and the risk of infantile colic: a follow-up study. Acta Paediatr. 2003;92:811-6.

9. Wachs TD. Models linking nutritional deficiencies to maternal and child mental health. Am J Clin Nutr. 2009;89:935S-9S.

10. Patel V, DeSouza N, Rodrigues M. Postnatal depression and infant growth and development in low-income countries: a cohort study from Goa, India. Arch Dis Child. 2003;88:34-7.

11. Rahmanifar A, Kirksey A, Wachs TD, McCabe G, Bishry Z, Galal OM, Harrison GG, Jerome NW. Diet during lactation associated with infant behavior and caregiver-infant interaction in a semirural Egyptian village. J Nutr. 1993;123:164-75.

12. McCullough AL, Kirksey A, Wachs TD, McCabe G, Bassily NS, Bishry Z, Galal OM, Harrison GG, Jerome NW. Vitamin B-6 status of Egyptian mothers-Relation to infant behavior and maternal-infant interactions. Am J Clin Nutr. 1990;51:1067-74.

13. Saha KK, Frongillo EA, Alam DS, Arifeen SE, Persson LA, Rasmussen K. Household food security is associated with growth of infants and young children in rural Bangladesh. Public Health Nutr. 2009;12:1556-62.

14. Saha KK, Tofail F, Frongillo EA, Rasmussen K, Arifeen SE, Persson LA, Huda SN, Hamadani JD. Household food security is associated with early childhood language development: results from a longitudinal study in rural Bangladesh. Child Care Health Dev. 2010;36:309-16.

15. Weaver LJ, Hadley C. Moving beyond hunger and nutrition: a systematic review of the evidence linking food insecurity and mental health in developing countries. Ecol Food Nutr. 2009;48:263-84.

16. Jones SJ, Frongillo EA. The modifying effects of Food Stamp Program participation on the relation between food insecurity and weight change in women. J Nutr. 2006;136:1091-4.

17. Whitaker RC, Phillips SM, Orzol SM. Food insecurity and the risks of depression and anxiety in mothers and behavior problems in their preschool-aged children. Pediatrics. 2006;118:e859-68.

18. Zaslow M, Bronte-Tinkew J, Capps R, Horowitz A, Moore KA, Weinstein D. Food security during infancy: implications for attachment and mental proficiency in toddlerhood. Matern Child Health J. 2009;13:66-80.

19. Bronte-Tinkew J, Zaslow M, Capps R, Horowitz A, McNamara M. Food insecurity works through depression, parenting, and infant feeding to influence overweight and health in toddlers. J Nutr. 2007;137:2160-5.

20. Cook JT, Frank DA. Food security, poverty, and human development in the United States. Ann N Y Acad Sci. 2008;1136:193-209.

21. Rose-Jacobs R, Black MM, Casey PH, Cook JT, Cutts DB, Chilton M, Heeren T, Levenson SM, Meyers AF, Frank DA. Household food insecurity: associations with at-risk infant and toddler development. Pediatrics. 2008;121:65-72.

22. Ashiabi GS, O'Neal KK. A framework for understanding the association between food insecurity and children's developmental outcomes. Child Dev Perspect. 2008;2:71-7.

23. Ensel WM, Linn L. The life stress paradigm and psychological distress. J Health Soc Behav. 1991;32:321-41.

24. Kaplan BJ, Crawford SG, Field CJ, Simpson JS. Vitamins, minerals, and mood. Psychol Bull. 2007;133:747-60.

25. Paulson JF, Dauber S, Leiferman JA. Individual and combined effects of postpartum depression in mothers and fathers on parenting behavior. Pediatrics. 2006;118:659-68.

26. Fram MS, Frongillo EA, Jones SJ, Williams RC, Burke MP, DeLoach KP, Blake CE. Children are aware of food insecurity and take responsibility for managing food resources. J Nutr. 2011;141:1114-9.

27. Cooper PJ, Tomlinson M, Swartz L, Landman M, Molteno C, Stein A, McPherson K, Murray L. Improving quality of mother-infant relationship and infant attachment in socioeconomically deprived community in South Africa: randomised controlled trial. BMJ. 2009;338:b974.

28. Frith AL. The influence of maternal nutritional and support interventions and stress on maternal-infant feeding interactions in Bangladesh. Ithaca (NY): Cornell University; 2006.

29. Wachs TD, Black MM, Engle PL. Maternal depression: a global threat to children's health, development, and behavior and to human rights. Child Dev Perspect. 2009;3:51-9.

30. Black MM, Baqui AH, Zaman K, McNary SW, Le K, Arifeen SE, Hamadani JD, Parveen M, Yunus MD, Black R. Depressive symptoms among rural Bangladeshi mothers: implications for infant development. J Child Psychol Psychiatry. 2007;48:764-72. 
31. Metallinos-Katsaras E, Gorman KS, Wilde P, Kallio J. A longitudinal study of WIC participation on household food insecurity. Matern Child Health J. 2011;15:627-33.

32. Ramachandran P. Poverty nutrition linkages. Indian J Med Res. 2007;126:249-61.

33. Bitler MP, Currie J. Does WIC work? The effects of WIC on pregnancy and birth outcomes. J Policy Anal Manage. 2005;24:73-91.

34. Frith AL, Frongillo EA, Ekstrom EC, Rasmussen K, Naved RT. Micronutrient supplementation affects maternal-infant feeding interaction and maternal distress in Bangladesh. Am J Clin Nutr. 2009;90:141-8.

35. Bodnar LM, Wisner KL. Nutrition and depression:iImplications for improving mental health among childbearing-aged women. Biol Psychiatry. 2005;58:679-85.

36. Barnard KE, Martell LH. Mothering. In: Bornstein MH, editor. Handbook of parenting. Mahwah (NJ): Lawrence Erlbaum Associates; 1995. p. 3-26.

37. Smith GC, Smith ME. First-trimester growth and the risk of low birth weight. N Engl J Med. 1998;339:1817-22.

38. Lechtig A, Yarbrough C, Delgado H, Habicht JP, Martorell R, Klein RE. Influence of maternal nutrition on birth-weight. Am J Clin Nutr. 1975;28:1223-33.

39. Ziv Y, Cassidy J. Maternal responsiveness and infant irritability: the contribution of Crockenberg and Smith's "Antecedents of mother-infant interaction and infant irritability in the first 3 months of life". Infant Behav Dev. 2002;25:16-20.

40. Gorman KS, Lourie AE, Choudry N. Differential patterns of development: the interaction of birth weight, temperament, and maternal behavior. J Dev Behav Pediatr. 2001;22:366-75.

41. van Ginneken J, Bairagi R, de Francisco A, Sarder AM, Vaughan JP. Health and demographic surveillance in Matlab: past, present and future. Dhaka (Bangladesh): International Centre for Diarrhoeal Disease Research, Bangladesh; 1998.

42. Alam DS, van Raaij JMA, Hautvast J, Yunus M, Fuchs GJ. Energy stress during pregnancy and lactation: consequences for maternal nutrition in rural Bangladesh. Eur J Clin Nutr. 2003;57:151-6.

43. National Research Council. Recommended dietary allowances. 10th ed. Washington, DC: National Academy Press; 1989.

44. Institute of Medicine. Dietary reference intakes for thiamin, riboflavin, niacin, vitamin B6, folate, vitamin B12, pantothenic acid, biotin, and choline. Washington, DC: National Academy Press; 1999.

45. Gwatkin DR, Rustein S, Johnson K, Pande RP, Wagstaff A. Socioeconomic differences in health, nutrition and population in Bangladesh: HNP/Poverty Thematic Group of the World Bank. Washington, DC: World Bank; 2000.

46. Frongillo EA, Chowdhury N, Ekström EC, Naved RT. Understanding the experience of household food insecurity in rural Bangladesh leads to a measure different from that used in other countries. J Nutr. 2003; 133:4158-62.
47. Engle PL, Ricciuti HN. Psychosocial aspects of care and nutrition. Food Nutr Bull. 1995;16:356-77.

48. Lobo ML. Parent-infant interaction during feeding when the infant has congenital heart disease. J Pediatr Nurs. 1992;7:97-105.

49. Goldberg S, Simmons RJ, Newman J, Campbell K, Fowler RS. Congenital heart disease, parental stress, and infant-mother relationships. J Pediatr. 1991;119:661-6.

50. Hurley KM, Black MM, Papas MA, Caulfield LE. Maternal symptoms of stress, depression, and anxiety are related to nonresponsive feeding styles in a statewide sample of WIC participants. J Nutr. 2008;138:799805. Erratum in: J Nutr. 2008;138(10):1982.

51. Teti D, Messinger D, Gelfand D, Isabella R. Maternal depression and the quality of early attachment: an examination of infants, preschoolers, and their mothers. Dev Psychol. 1995;31:364-76.

52. Martorell GA, Bugental DB. Maternal variations in stress reactivity: implications for harsh parenting practices with very young children. J Fam Psychol. 2006;20:641-7.

53. McGrath JM, Records K, Rice M. Maternal depression and infant temperament characteristics. Infant Behav Dev. 2008;31:71-80.

54. Langenberg P, Ballesteros M, Feldman R, Damron D, Anliker J, Havas S. Psychosocial factors and intervention-associated changes in those factors as correlates of change in fruit and vegetable consumption in the Maryland WIC 5 a day promotion program. Ann Behav Med. 2000; 22:307-15.

55. Tofail F, Persson LA, Arifeen SE, Hamadani JD, Mehrin F, Ridout D, Ekström EC, Huda SN, Grantham-McGregor SM. Effects of prenatal food and micronutrient supplementation on infant development: a randomized trial from the Maternal and Infant Nutrition Interventions, Matlab (MINIMat) study. Am J Clin Nutr. 2008;87:704-11.

56. Clarke L, Heasman L, Juniper D, Symonds M. Maternal nutrition in earlymid gestation and placental size in sheep. Br J Nutr. 1998;79:359-64.

57. Crnic KA, Greenberg MT, Ragozin AS, Robinson NM, Basham RB. Effects of stress and social support on mothers and premature and fullterm infants. Child Dev. 1983;54:209-17.

58. Crockenberg SB, Smith D. Infant irritability, mother responsiveness, and social support influences on the security of infant-mother attachment. Child Dev. 1981;52:857-65.

59. Siefert K, Heflin C, Corcoran M, Williams D. Food insufficiency and physical and mental health in a longitudinal survey of welfare recipients. J Health Soc Behav. 2004;45:171-86.

60. Feldman PJ, Dunkel-Schetter C, Sandman CA, Wadhwa PD. Maternal social support predicts birth weight and fetal growth in human pregnancy. Psychosom Med. 2000;62:715-25.

61. Collins NL, Dunkel Schetter C, Lobel M, Scrimshaw S. Social support in pregnancy: psychosocial correlates of birth outcomes and postpartum depression. J Pers Soc Psychol. 1993;65:1243-58.

62. Aboud FE. Evaluation of an early childhood parenting programme in rural Bangladesh. J Health Popul Nutr. 2007;25:3-13. 